\title{
INVESTIGATION OF THE INTAKE OF A STATIONARY GAS TURBINE TO PREVENT ICE FORMATION
}

\author{
Dipl.-Ing. Andreas TRAMPOSCH, prof. Dipl.-Ing Vojtech MOLNÁR, DrSc., \\ doc. Ing. František RIDZON, CSc.
}

Faculty of Mechanical Engineering, Slovak University of Technology Bratislava, Nám. slobody 17, 81231 Bratislava, Slovakia, andreas.tramposch@fh-joanneum.at, vojtech.molnar@stuba.sk, frantisek.ridzon@stuba.sk

\begin{abstract}
Repeated emergency shutdowns of a stationary gas turbine under conditions of subfreezing temperatures and moist air have led to the suspicion that ice formation in the intake channel and compressor may be a contributing factor. To understand the reason, why the installed ice protection system is not effective, a numerical investigation of the intake channel with the installed hot air ice protection system has been performed. It is shown that mixing of hot air with cold outside air is incomplete, explaining the ice accretion.
\end{abstract}

Keywords: CFD simulation, Gas turbine icing, Hot air ice protection system, Mixing

\section{INTRODUCTION}

Modern industrial gas turbine installations in power and gas industry are based on aero derivates engines. The gas generator is used to drive a power turbine on a separate shaft. An inlet duct system with integrated air filtering and anti-icing protection unit and an exhaust duct system are additional equipments for industrial gas turbines.

Anti-icing systems are designed to inhibit ice formation on inlet components in order to protect the gas turbine from these hazards. The standard gas generator is outfitted with an anti-icing control system. Usually a set of probes is distributed circumferentially in front of the compressor inlet guide vanes. Each of the probes can activate the compressor bleed anti-icing system to start heating the inlet air. The heating occurs by mixing the hot compressor bleed air with the inlet air in the inlet duct.

A simple cost effective configuration of perforated tubes is usually applied to achieve the required effect. The design should ensure uniform air temperature distribution just before the gas generator compressor inlet. If the temperature field is non-uniform due to the design or due to the mixing process, the anti-icing system can evaluate it as emergency gas turbine stop.

Both CFD analysis and experimental research are used to optimize the anti-icing protection unit. In this paper the results of a CFD analysis are reported.

\section{DESCRIPTION OF THE CONSIDERED INSTALLATION}

The ice protection system of the considered stationary gas turbine utilizes hot, dry air $\left(350^{\circ} \mathrm{C}\right)$ for this purpose, extracted from the $16^{\text {th }}$ stage of the compressor. The hot air is ducted to the inlet section upstream of the compressor and is discharged into the ingested cold air via two horizontal, circular ducts running perpendicular to the cold air flow. The two discharge ducts for 
the hot air contain five rows of holes on the upper and on the lower side of each duct, through which hot air is discharged into the intake channel and is mixed with the cold air.

If the hot and cold air streams would mix well, no ice accretion on the gas turbine should occur. However, operational experience of the considered gas turbine with repeated emergency shutdowns led to the suspicion that ice formation is not avoided.

In order to find the reason for the incomplete mixing of hot and cold air, a numerical simulation is performed before detailed measurements will be carried out.

In figure 1 the Computer Aided Design (CAD) model of the intake channel and the hot air distribution system are shown. The investigated intake channel is 3 meters wide, 2.4 meters high and 8 meters long. This geometry is the basis for all investigations described in the current paper.

Figure 2 shows a photo of the intake channel with the two horizontal ducts of the hot air system. On the lower duct a row of holes is visible, through which the hot air flows out vertically. The view is in direction of the flow straightener in front of the compressor.

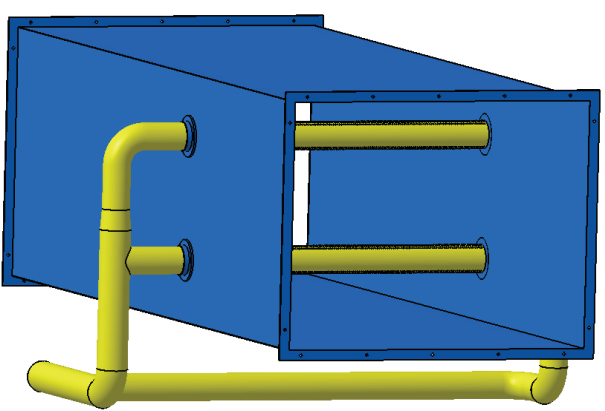

Fig. 1: CAD model of gas turbine intake with hot air distribution system

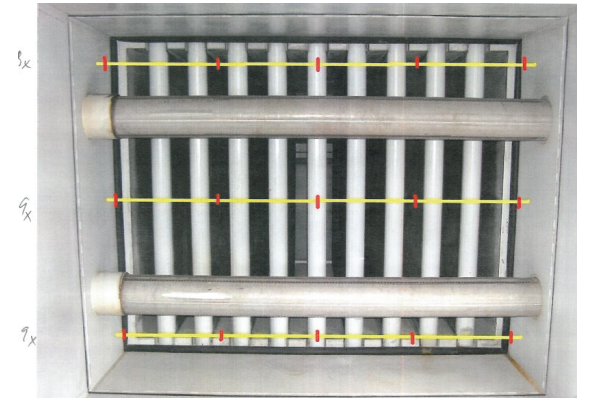

Fig. 2: Intake channel with proposed temperature measurement positions (yellow lines)

\section{SET UP FOR NUMERICAL SIMULATION}

The numerical simulation, described in this paper was performed using CFX v12.1 [1]. The horizontal ducts, running perpendicular to the flow direction, induce a complex turbulent flow field with high swirl. In order to resolve the different length turbulent scales of the hot and cold air mixing and the transient behaviour of the vortex shedding behind the hot air ducts, a Large Eddy Simulation (LES) would be ideal. However, the requirements for an LES model with respect to grid size and grid quality (cf. [5]) in conjunction with the need for a Courant-Friedrichs-Lewy (CFL) number near 1 implies very long calculation times for LES-simulations.

An alternative would be to employ the SAS-SST turbulence model, which allows resolving the turbulent spectrum in unstable flow conditions. The SAS concept is based on the introduction of the von Karman length scale into the turbulence scale equation. The information provided by the von Karman length-scale allows the SAS model to adjust dynamically to resolved turbulent flow structures in a simulation, which results in an LES-like behaviour in unsteady regions of the flow field. At the same time, the model provides standard Reynolds-averaged Navier-Stokes simulation (RANS) capabilities in stable flow regions. For further details on the SAS-SST turbulence model, the reader is referred to references [3] and [6].

Due to the fact that the considered geometry is complex and requires a relatively large number of cells, the turbulence model selected in the present investigation was a standard k-epsilon turbulence model (cf. [4]). The k-epsilon turbulence model is a stationary RANS turbulence model, 
using an eddy viscosity two equation approach. It includes two transport equations to represent the turbulent properties of the flow. This allows to account for history effects like convection and diffusion of turbulent energy. The first transported variable is turbulent kinetic energy, $\mathrm{k}$. The second transported variable is the turbulent dissipation, $\varepsilon$.

The stationary simulation is intended to provide initial values for a possible subsequent, more thorough transient simulation.

The transport of moisture, entering the intake channel, is being modelled by a multiphase simulation based on a homogenous Euler-Euler method (cf. [1]).

In a homogeneous multiphase flow, the flow field as well as the temperature and the turbulence are shared by all fluids - only the mass fractions are changing. The first phase simulated is dry air (ideal gas) and the second phase is water vapour.

The inflow boundary condition is a fixed mass flow of $64.9 \mathrm{~kg} / \mathrm{s}(233649 \mathrm{~kg} / \mathrm{h})$. The relative humidity is set to $70 \%$ and represented by appropriate volume fractions of dry air and water vapour. The absolute moisture content is calculated by equation 1 [2] under consideration of the thermophysical properties listed in table 1 .

$$
x=\frac{m_{d}}{m_{\text {air }}}=\frac{M_{H 2 O}}{M_{\text {air }}} \frac{\varphi p_{s}}{p-\varphi p_{s}}=0.622 \frac{\varphi p_{s}}{p-\varphi p_{s}}
$$

\begin{tabular}{|l|l|}
\hline Total pressure $\mathrm{p}[\mathrm{hPa}]$ & 1010 \\
\hline Total bulk mass flow $[\mathrm{kg} / \mathrm{h}]$ & 233640 \\
\hline Relative humidity $\varphi[\%]$ & 70 \\
\hline Intake air temperature $\mathrm{T}\left[{ }^{\circ} \mathrm{C}\right]$ & 0.00 \\
\hline Density of intake air flow $\left[\mathrm{kg} / \mathrm{m}^{3}\right]$ & 1.29 \\
\hline Saturation water pressure $\mathrm{p}_{\mathrm{s}}[\mathrm{kPa}]$ & 0.611 \\
\hline Molar gas constant of water $\mathrm{R}_{\mathrm{H} 2 \mathrm{O}}[\mathrm{J} / \mathrm{kgK}]$ & 461.50 \\
\hline Molar gas constant of dry air $\mathrm{R}_{\text {air }}[\mathrm{J} / \mathrm{kgK}]$ & 287.20 \\
\hline Molar mass of water $\mathrm{M}_{\mathrm{H} 2 \mathrm{O}}[\mathrm{kg} / \mathrm{kM}]$ & 18.015 \\
\hline Molar mass of dry air $\mathrm{M}_{\text {air }}[\mathrm{kg} / \mathrm{kM}]$ & 28.9626 \\
\hline
\end{tabular}

Tab. 1: Thermophysical properties

Considering the ratio of the molar mass of water and dry air as well as the saturation vapor at a temperature of $0^{\circ} \mathrm{C}$ [2], the absolute moisture content is calculated to be 0.0026717 . This leads to a mass flux of $624.22 \mathrm{~kg} / \mathrm{h}$ of water vapor and $233015.78 \mathrm{~kg} / \mathrm{h}$ of dry air at the inlet, which set as inlet boundary condition for the intake channel.

The air entering the duct system is assumed to be dry air (ideal gas) without water vapor content at a temperature of $300{ }^{\circ} \mathrm{C}$. The mass flow is set to $6060 \mathrm{~kg} / \mathrm{h}$.

To allow determination of the mass fraction of hot air stemming from the compressor, an additional transport equation for the mass fraction $\varphi$ is integrated. In this transport equation, $\varphi$ is treated as a passive scalar.

$$
\frac{\partial(\rho \varphi)}{\partial t}+\nabla \cdot(\rho \vec{U} \varphi)=\nabla \cdot\left(\left(\rho D_{\Theta}+\frac{\mu_{t}}{S c_{t}}\right) \nabla \varphi\right)+S_{\varphi}
$$

For the inlet of the hot air supply duct the mass fraction was set to 1 (equals $100 \%$ ). At the inlet of the intake channel this variable was set to zero. Due to the assumption that convective forces are dominating and therefore a good mixture of hot and cold air is present, the molecular diffusivity is 
being neglected. Therefore the molecular diffusivity coefficient $\mathrm{D}_{\Theta}$ was set to zero for this transport equation.

Heat transfer through the duct walls by conduction is modelled by employing a conjugate heat transfer model, which enables the creation of solid regions, representing e.g. the duct walls, in which no flow is present and thus only the energy equation needs to be solved. The energy equation can account for heat transport due to solid motion, conduction, and volumetric heat sources (cf. [1]):

To meet the high requirements for the spatial discretization (resolution of the detailed geometry, an adequate mesh quality and a sufficient number of total cell elements to perform the simulation at an affordable calculation time), a hybrid mesh was used within this investigation.

While the intake channel and the duct system consist of an unstructured mesh (see figure 3 and figure 4), the horizontal ducts with the drilled holes consist of a hexaeder mesh (see figure 5 and figure 6). The complete hybrid mesh reaches a total cell count of about 6 million cells.

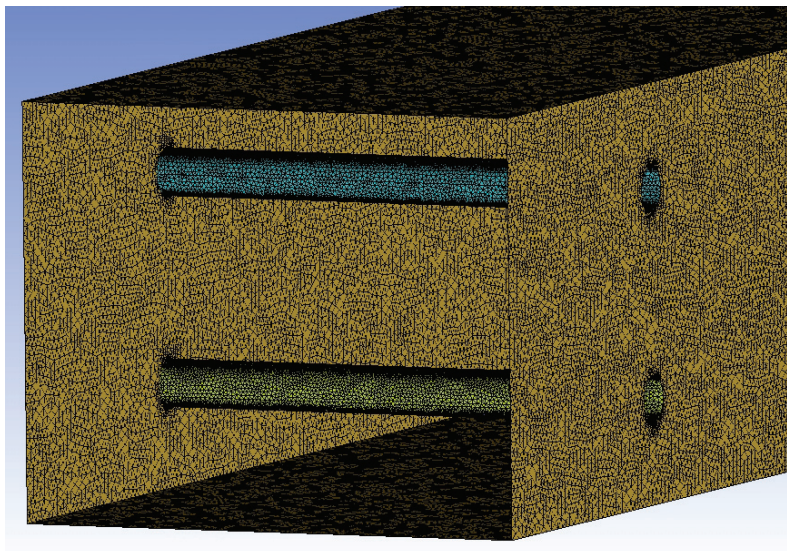

Fig. 5: Unstructured surface mesh of intake channel

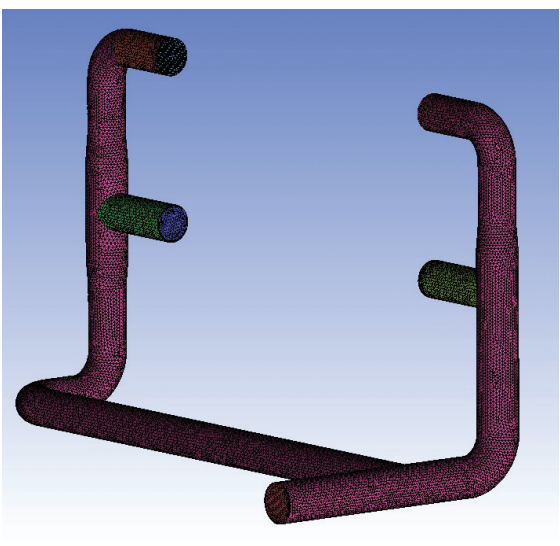

Fig. 6: Unstructured surface mesh of hot air duct system

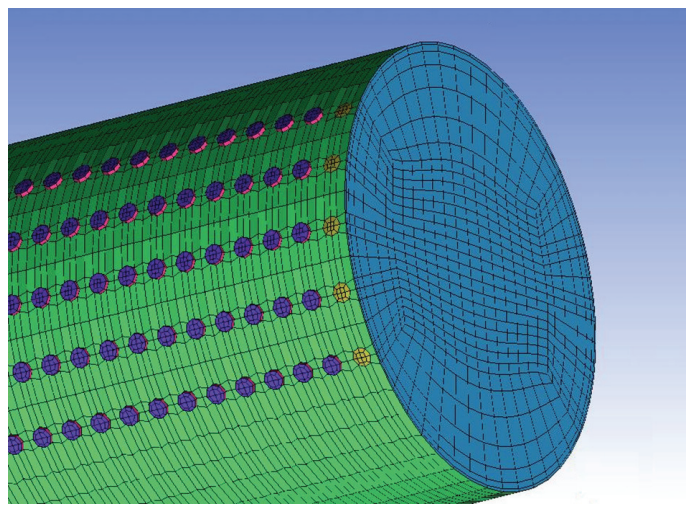

Fig. 5: Structured mesh of horizontal duct (fluid domain)

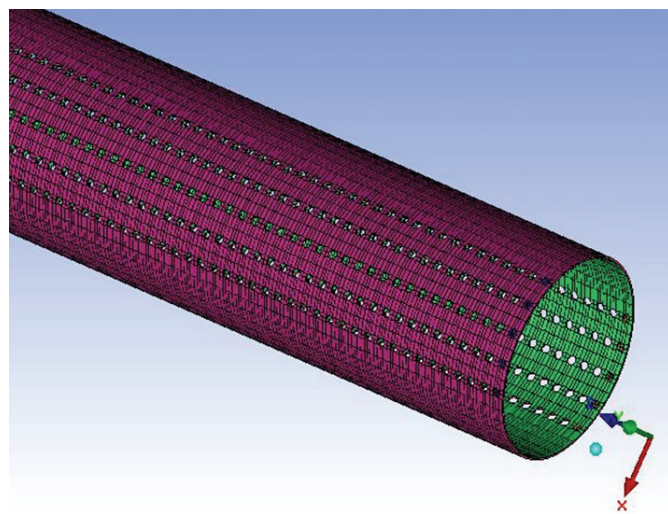

Fig. 6: Structured mesh of solid domain (solid domain) 
GGIs (General Grid Interfaces) connect the structured hexaeder meshes with the unstructured surface meshes. The treatment of the fluxes on the interfaces is fully implicit and conservative in mass, momentum and energy [1].

\section{RESULTS}

Figure 7 shows an isosurface enclosing the volume with a hot air mass fraction of more than $10 \%$. It is clearly visible from the results that the hot air, flowing out of the hot air ducts in vertical direction, is quickly entrained by the intake channel flow and redirected into the main flow direction. It is obvious that the hot air mass flow of the lower duct is discharged relatively uniformly into the intake channel flow along the duct length. However in contrast, the hot air mass flow leaving the upper supply duct is very non-uniform. While on one side a high mass flow of hot air is present, on the other side almost no hot air is discharged into the intake channel. This may be the reason for the icing problems observed on this wall side.

In figure 8 , three temperature cut planes along the intake channel in flow direction are shown. In figure 9, six temperature cut planes across the intake channel perpendicular to the flow direction are depicted. The mixture of the hot air with the cold air leads to a maximum temperature increase of $7.4^{\circ} \mathrm{C}$. Additionally, it is obvious that because of the non-uniform distribution of hot air the temperature distribution is also non-uniform. With increasing flow length an improvement of the air mixture is observable.

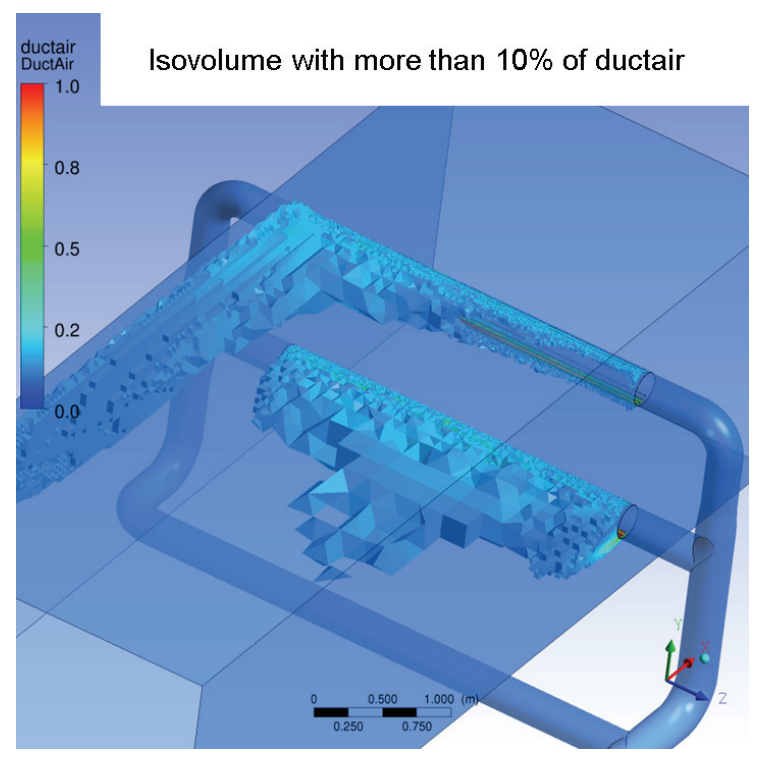

Fig. 7: Isosurfaces around those volume elements with more than $10 \%$ duct_air

Figure 10 provides an explanation for the observed non-uniformity. Because of the resulting pressure distribution in the duct system, an unequal discharge of hot air mass flow by the horizontal ducts follows, leading to more than $70 \%$ of the hot air mass flow being distributed by the lower duct. 
At the T-junction $\mathrm{T} 1$ on the right side of the horizontal ducts, all of the total mass flow of $1.68 \mathrm{~kg} / \mathrm{s}$ of hot air entering the duct system (red streamlines) is flowing straight ahead to the right side of the horizontal ducts.

Additionally, a part of the hot air leaving the upper duct $(0.11 \mathrm{~kg} / \mathrm{s}$, blue streamlines $)$ is joining the fresh hot air at the T-junction T1.

This mixture is than separated at the second T-junction T2. There $1.55 \mathrm{~kg} / \mathrm{s}$ enter the upper duct and only $0.23 \mathrm{~kg} / \mathrm{s}$ the lower duct. The largest part $(0.99 \mathrm{~kg} / \mathrm{s})$ of the $1.1 \mathrm{~kg} / \mathrm{s}$ of air leaving the upper duct is entering the lower duct on the left side.

As a result, a mass flow of $1.22 \mathrm{~kg} / \mathrm{s}$ of hot air is leaving the lower duct and only $0.45 \mathrm{~kg} / \mathrm{s}$ is leaving the upper duct.

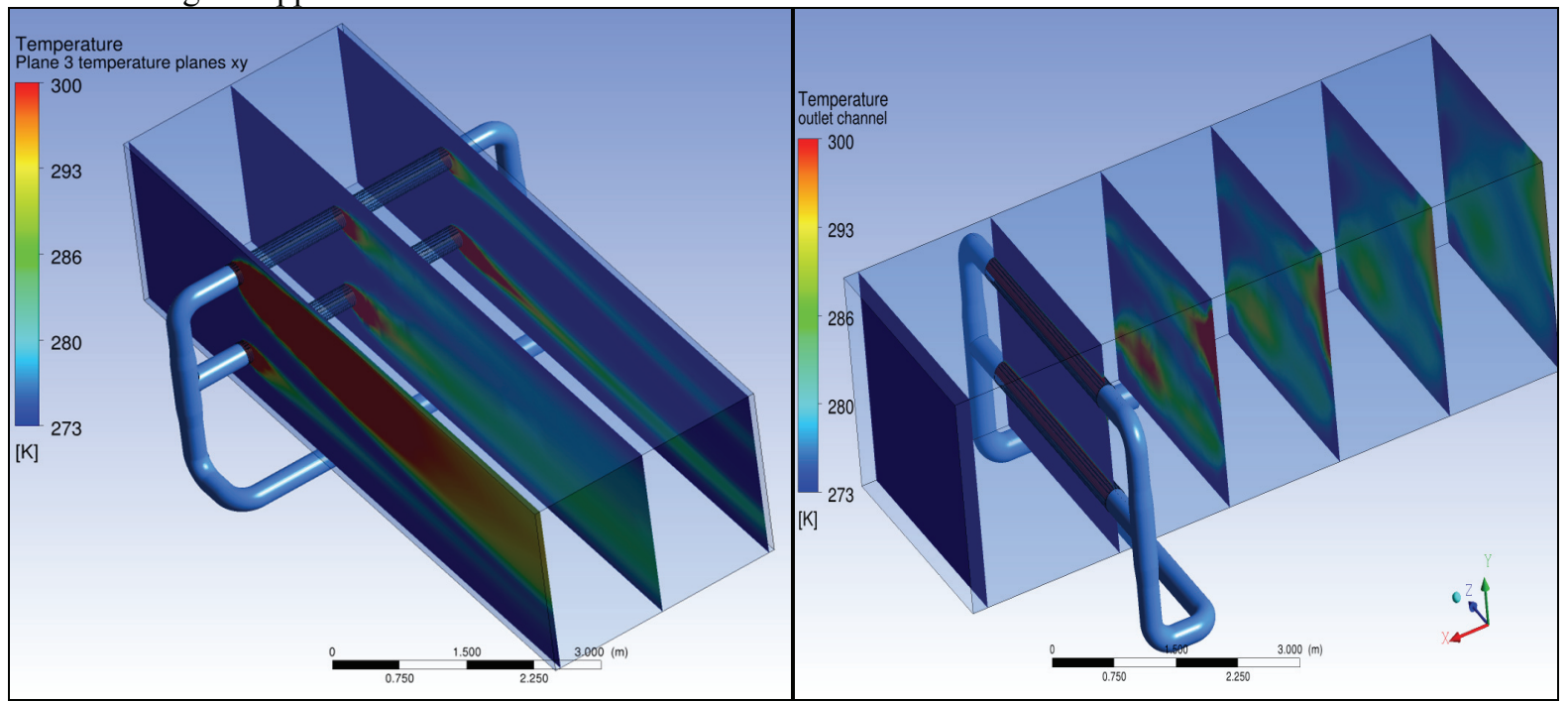

Fig. 8: Temperature cut planes along intake channel in flow direction.

Fig. 9: Temperature cut planes in the intake channel perpendicular to flow direction 


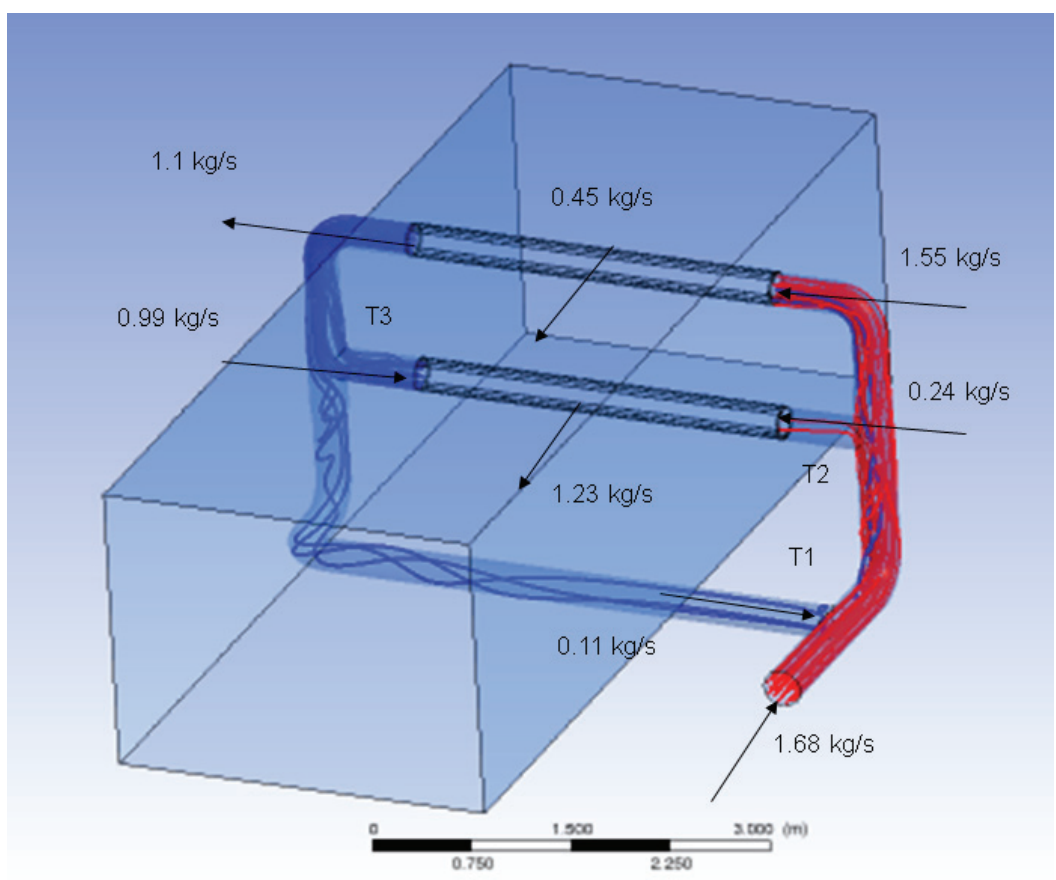

Fig. 10: Mass flux distribution of hot air in hot air duct system

\section{CONCLUSION}

The investigation described in this paper shows that there is a significant non-uniform distribution of hot air leaving the horizontal supply ducts inside the intake channel. This is caused by the prescribed geometry and the resulting pressure distribution in the duct system.

The results of the numerical simulation match with the operational experience. It is suggested that in the frame of the simultaneous detailed measurements, the temperature in front of the flow straightener should be measured and compared with the numerical results. An appropriate position for temperature measurements is marked in Fig. 2 by three yellow lines. In order to find improvements for the current situation (e. g. adjustment of restrictor plates, influencing the pressure distribution in the duct system), numerical simulations of an updated geometry could be performed in a relatively short time frame using the existing mesh and simulation definition.

\section{ACKNOWLEDGMENT}

I would like to thank my scientific supervisor, Prof. Dipl.-Ing. Vojtech Molnar, DrSc., for pointing me to this interesting problem and his continued support during this investigation.

\section{REFERENCES}

[1] ANSYS-CFX, Version 12.1, Copyright 1996-2009 ANSYS Europe LTd. 2009.

[2] CERBE, G. and WILHELMS, G., Technische Thermodynamik. 14. Auflage, Hanser Verlag, 2007. 
[3] MENTER, F. R., et. al., Steady and unsteady flow modelling using the $k-\sqrt{ } k L$ turbulence model. J. Heat Mass Transfer. 5. 2006.

[4] LAUNDER, B. E., and SHARMA, B. I., Application of the Energy Dissipation Model of Turbulence to the Calculation of Flow Near a Spinning Disc. Lett. Heat Mass Transfer, vol. 1, no. 2, pp. 131-138, 1974.

[5] GYLLENRAM and NILSSON, H., Design and validation of a scale-adaptive filtering technique for LNR turbulence modeling of unsteady flow. J. Fluid Eng., 2008.

[6] MENTER, F.R. and EGOROV, Y., Scale-adaptive simulation model using two-equation models. AIAA conference, Reno, 2005. 